\title{
Vulnerabilidade ambiental da costa oeste da Região Salgado Paraense (Estado do Pará, Norte do Brasil)
}

\section{Tatiana Chagas Prata ${ }^{1}$ e Aline Maria Meiguins de Lima}

\author{
${ }^{1}$ Universidade Federal do Pará. Instituto de Geociências. Faculdade de Geologia. \\ Rua Augusto Corrêa, 01. Guamá. Belém-PA, Brasil (CEP 66075-110). E-mail: \\ tatianaprata06@gmail.com. \\ ${ }^{2}$ Universidade Federal do Pará. Instituto de Geociências. Programa de \\ Pós-Graduação em Ciências Ambientais. Rua Augusto Corrêa, 01. Guamá. \\ Belém-PA, Brasil (CEP 66075-110).
}

Resumo. 0 crescente aumento de áreas desmatadas e a expansão da ocupação desordenada na planície costeira paraense indicam a necessidade de estudos acerca das áreas mais vulneráveis a potenciais impactos ambientais. Assim, elaborou-se uma carta de vulnerabilidade ambiental da zona costeira oeste da Região Salgado Paraense (Estado do Pará, Norte do Brasil), considerando os processos costeiros naturais e a influência antrópica que interferem no equilíbrio desta região. Utilizaram-se ferramentas de geoprocessamento para a análise do comportamento do terreno a partir da integração, por álgebra de mapas, de diversas informações especializadas na forma de mapas e cartas temáticos (geologia, geomorfologia, pedologia, vegetação e uso e ocupação da terra), em um Sistema de Informações Geográfica (SIG). Os resultados obtidos demostram que cerca de $28 \%$ da área apresenta vulnerabilidade muito alta e alta, que acarretam a atenção prioritária visando à determinação de medidas adequadas para o desenvolvimento sustentável e a reestruturação dos ambientes da região, buscando minimizar e evitar os impactos ambientais a fim de reduzir perdas ambientais, sociais e econômicas.

Palavras-chave: Vulnerabilidade ambiental; Geoprocessamento; Álgebra de mapas; Zona costeira.

\begin{abstract}
Environmental vulnerability of the west coast of Salgado Paraense (State of Pará, North Brazil). The growing increase in deforested areas and the expansion of disordered occupation in the coastal plain of Pará indicate the need for studies about the areas most vulnerable to potential environmental impacts. A chart of the environmental vulnerability of the west coastal zone of Salgado Paraense Region was developed, considering the natural coastal processes and the
\end{abstract}

Recebido

$19 / 04 / 2021$

Aceito

$24 / 11 / 2021$

Disponível on line $24 / 11 / 2021$

Publicado

$31 / 12 / 2021$

Acesso aberto

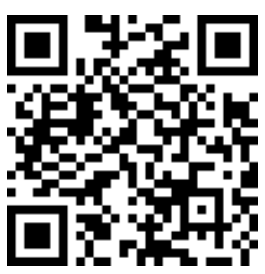

ORCID

(D) 0000-0001-9318-2541 Tatiana Chagas Prata

(1) 0000-0002-0594-0187 Aline Maria Meiguins de Lima 
anthropic influence that interfere in the balance of this region. Geoprocessing tools were used to analyze the behavior of the terrain from the integration of various specialized information in the form of maps and thematic maps (geology, geomorphology, pedology, vegetation and land use and occupation), in a Geographic Information System (GIS). The results obtained show that about $28 \%$ of the area corresponds presents of very high and high vulnerability. They give priority attention to the determine action of appropriate measures for sustainable development and the restructuring of the region's environments, seeking to minimize and avoid environmental impacts to reduce environmental, social, and economic losses.

Keywords: Environmental vulnerability; Geoprocessing; Map algebra; Coast zones.

\section{Introdução}

A conservação dos ecossistemas costeiros é de extrema importância, tendo em vista o seu potencial ecológico, assim como, o seu interesse para o desenvolvimento socioeconômico. Agressões antrópicas, como ocupação desordenada e uso indevido do solo, podem gerar modificações nos processos associados a estes sistemas. 0 estudo destes e suas variações, sejam por causas naturais ou por influência antrópica frente à ocupação das zonas costeiras, têm orientado as decisões necessárias e intervenções adequadas, visando à redução dos impactos ambientais e proteção dessas áreas.

Os ambientes podem apresentar diferentes susceptibilidades às mudanças, tanto naturais quanto antrópicas. Determinar o grau desta susceptibilidade é determinar o quanto este ambiente é vulnerável a tais mudanças. A determinação das vulnerabilidades pode ser determinada por diversos índices, sendo adotado nesta pesquisa o índice de vulnerabilidade ambiental, que se refere à vulnerabilidade do meio ambiente em relação às mudanças antrópicas (Crepani et al., 2001; Grigio, 2003; Tagliani, 2003).

A determinação da vulnerabilidade ambiental das zonas costeiras é de significativa importância, uma vez que, a análise da vulnerabilidade de uma região permite identificar e avaliar espacialmente áreas de maior susceptibilidade a mudanças, assim como reconhecer as causas das modificações, permitindo a determinação de medidas adequadas para o desenvolvimento sustentável e a reestruturação dos ambientes da região, buscando minimizar e evitar os impactos ambientais causados por atividades naturais ou antrópicas (Boori e Amaro, 2011a; Oliveira, 2017).

Tendo em vista que, no Estado do Pará, cerca de 43\% da população reside na zona costeira, ao longo do qual se alternam diversos ecossistemas importantes do ponto de vista ecológico e social (Boulhosa, 2006), esse tipo de análise ambiental auxilia políticas públicas, existentes nas diversas instituições e agências governamentais, como o Plano Diretor e o Zoneamento Ecológico-Econômico.

Dessa forma, este artigo objetiva contribuir para o entendimento da vulnerabilidade ambiental de uma planície costeira ao longo da costa de manguezais do nordeste do Estado do Pará, gerando produtos que podem auxiliar a gestão costeira integrada da região. 


\section{Material e métodos}

\section{Localização}

A área de estudo está localizada na porção oeste da Região Salgado Paraense, localizada no nordeste do Estado do Pará. A área compreende a zona costeira da região, com área de aproximadamente 1.716,6 km², que engloba a porção territorial dos Municípios de Curuçá, São Caetano de Odivelas, Vigia e São João da Ponta (Figura 1). Nesta área estão inseridas as Reservas Extrativistas (RESEX) Mãe Grande de Curuçá, São João da Ponta e Mocapajuba.

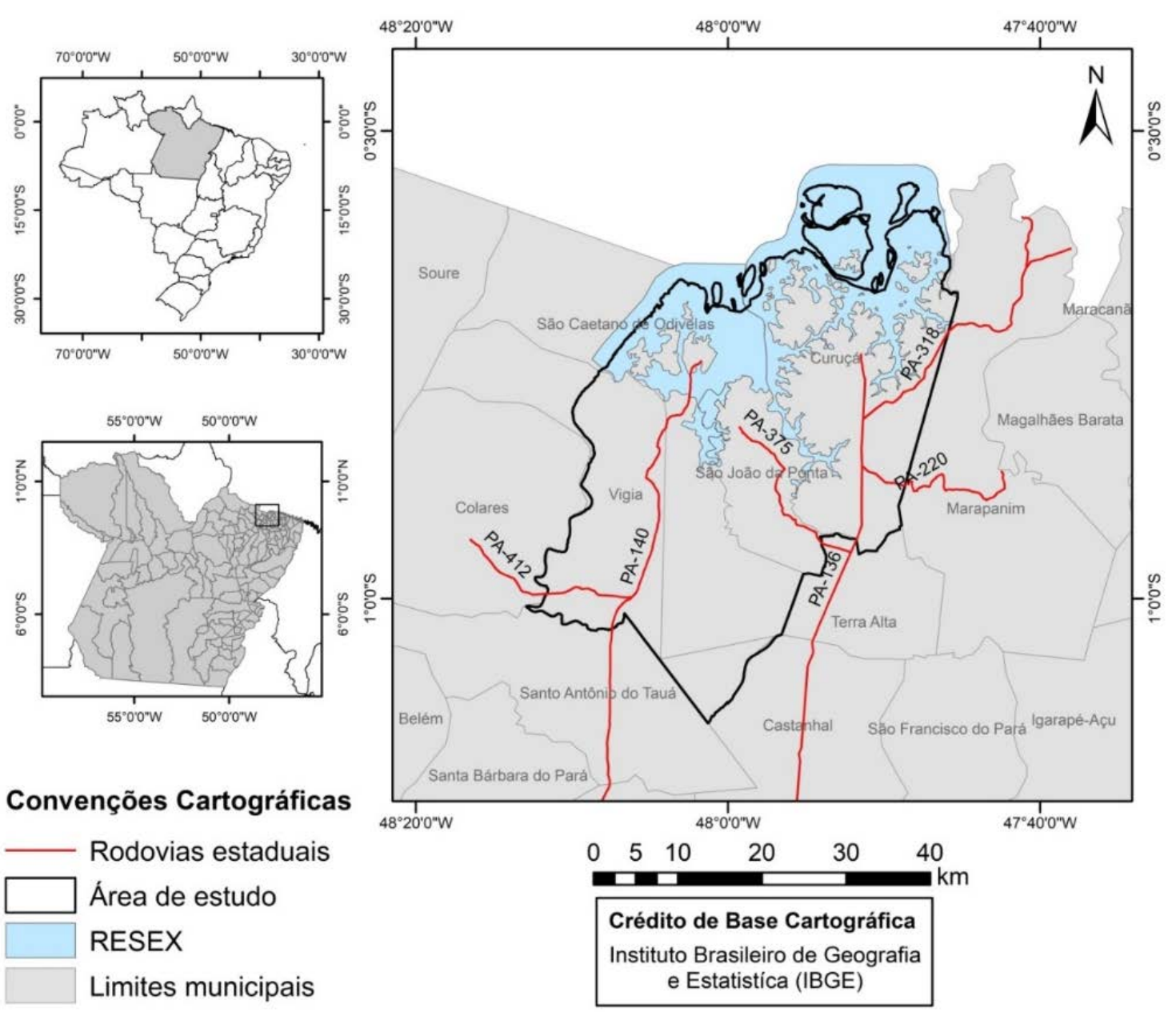

Figura 1. Mapa de localização da área de estudo.

\section{Geração das cartas de uso e ocupação da terra e de vegetação}

A definição de cada classe de uso e ocupação da terra e de vegetação ocorreu a partir da identificação das unidades de paisagem em imagens do satélite GeoEye (obtidas em 06 de novembro de 2018) posteriormente georreferenciadas. Cada unidade de paisagem foi vetorizada, sendo que cada polígono passou a representar um fragmento de tipo de cobertura e uso da terra ou de vegetação. A classificação foi auxiliada pela criação de uma Chave de Interpretação para cada tema na qual categoriza características como cor, textura, arranjo e forma, permitindo assim a identificação de cada classe (IBGE, 2013). 
A interpretação dessas categorias para cada carta utilizou como base metodológica a orientação do Manual Técnico de Uso das Terras (IBGE, 2013) e do Manual Técnico Vegetação Brasileira (IBGE, 2012).

\section{Geração da carta de geomorfologia}

A carta de geomorfologia foi gerada a partir da interpretação e reconhecimento visual das imagens RapidEye, assim como, a partir dos dados de elevação das imagens SRTM. Inicialmente foi feito o mosaico das imagens RapidEye, as cenas utilizadas apresentam um período amostral variando de 2012 a 2015, já que se buscou com menor cobertura de nuvens, que é um problema recorrente nesta região. A composição colorida RGB das bandas utilizada foi 5, 4 e 3. Subsequentemente, foi aplicado o realce, através da manipulação dos histogramas de cada banda espectral, o que permitiu a melhora da qualidade visual da imagem, tornando mais fácil o discernimento dos aspectos presentes no terreno. Com o Modelo Digital de Elevação (MDE), produzido pela missão SRTM (Shuttle Radar Topography Mission), foram geradas imagens derivadas associadas ao realce de relevo sombreado e a carta de declividade, em programas específicos de geoprocessamento e tratamento digital de imagens.

A partir desses produtos, as Unidades de Terreno foram compartimentadas a partir da delimitação de diferentes aspectos texturais das imagens SRTM por representar padrões de formas de relevo semelhantes entre si. As feições morfológicas de cada unidade foram descritas, de forma qualitativa, onde foram analisados os elementos que compõem o relevo (geometrias de topo, vertente e vale). Tendo o auxílio da classificação visual das imagens RapidEye, a partir da utilização de critérios como padrão, textura, cores, tons e arranjos espaciais das imagens. A classificação das Unidades de Terreno utilizou como base metodológica a orientação do Manual Técnico de Geomorfologia (IBGE, 2009), compartimentando a área de estudo em polígonos que representam as diferentes unidades.

\section{Geração da carta de vulnerabilidade ambiental}

A partir da avaliação de diferentes temas e características, foram selecionadas cinco cartas temáticas para a confecção da carta de vulnerabilidade ambiental da área: geomorfologia, pedologia, geologia, vegetação, e uso e ocupação da terra. Primeiramente, foi realizado o reconhecimento em campo da área de estudo, identificando, georreferenciando e validando as informações geradas pela cartografia elaborada e dados sobre geologia e pedologia obtidos a partir de pesquisas cartográficas. Esta ocorreu durante no mês de dezembro, quando a maior parte dos cursos d'água interiores estava com sua menor área de alagada, possibilitando assim identificar a ocorrência de feições erosivas e deposicionais. Posteriormente, os cinco documentos cartográficos verificados em campo foram reamostrados para arquivos do tipo raster. E então, as imagens, individualmente, foram reclassificadas para uma escala de valores de 1 a 5 , que representam as diferentes classes de vulnerabilidade para característica do meio (Tabela 1).

A escala segue a lógica de que quanto maior a vulnerabilidade, maior o valor na escala. Na valoração atribuída foram utilizados os conceitos já apresentados em Crepani et al. (2001), que admitem "o estágio de evolução morfodinâmica das unidades territoriais básicas", onde os menores valores favorecem a estabilidade e quanto maior for a atribuição do peso, mais instável o meio se torna (com intervalo adaptado para 1 a 5). Foram empregados também de forma complementar as observações de campo e as informações oriundas de pesquisas efetuadas na região (Souza Filho e El-Robrini, 1998; Lara, 2003; El-Robrini e Mácola, 2004; França e Souza Filho, 2006; e Rodrigues e Souza Filho, 2011). 
A caracterização da vulnerabilidade das litologias está relacionada ao grau de coesão da mesma uma vez que nas rochas pouco coesas irão prevalecer os processos erosivos, esculpindo assim o relevo (morfogênese), enquanto nas mais coesas prevalecem os processos de intemperismo e formação dos solos (pedogênese).

Tabela 1. Classes de vulnerabilidade de geologia, pedologia, vegetação, geomorfologia e uso e ocupação do solo da área.

\begin{tabular}{|c|c|c|}
\hline Tema & Classes/Unidades & Valor \\
\hline \multirow{3}{*}{ Geologia } & Grupo Barreiras (arenitos, argilitos, e conglomerados) & 3 \\
\hline & $\begin{array}{l}\text { Sedimentos Pós-Barreiras } \\
\text { semiconsolidadas) }\end{array}$ & 4 \\
\hline & $\begin{array}{l}\text { Depósitos litorâneos (areia, argila, silte) } \\
\text { Depósitos aluvionares (areia, argila, cascalho, silte) }\end{array}$ & 5 \\
\hline \multirow{3}{*}{ Pedologia } & Latossolo amarelo & 1 \\
\hline & Espodossolo Ferrihumilúvico & 3 \\
\hline & $\begin{array}{l}\text { Plinossolo Pétrico, Gleissolo Tiomórfico, Gleissolo } \\
\text { Neossolos Flúplico, } \\
\text { Flúvicos, Neossolos Quartzarênicos }\end{array}$ & 5 \\
\hline \multirow{5}{*}{ Vegetação } & Floresta Ombrófila Densa Aluvial & 1 \\
\hline & Formação Pioneira com influência fluviomarinha arbórea & 2 \\
\hline & Vegetação Secundária & 3 \\
\hline & $\begin{array}{l}\text { Formação Pioneira com influência marinha arbustiva, } \\
\text { Área antrópica agrícola }\end{array}$ & 4 \\
\hline & $\begin{array}{l}\text { Formação Pioneira com influência fluviomarinha herbácea, } \\
\text { Formação Pioneira com influência fluvial e/ou lacustre herbácea }\end{array}$ & 5 \\
\hline \multirow{4}{*}{ Geomorfologia } & Dissecação Homogênea: topos tabulares & 2 \\
\hline & Planície Fluvial com lagos & 3 \\
\hline & Planície fluvial, Planície fluviomarinha & 4 \\
\hline & Dunas, Planície marinha, Dissecação Homogênea: vales abertos & 5 \\
\hline \multirow{4}{*}{$\begin{array}{l}\text { Uso e ocupação da } \\
\text { terra }\end{array}$} & Área florestal, Reserva Extrativista & 1 \\
\hline & Vegetação secundária, Área campestre & 3 \\
\hline & Área antrópica agrícola, Terra úmida & 4 \\
\hline & Solo Exposto, Cidade, Vila, Povoado, Açude/lago & 5 \\
\hline
\end{tabular}

Fonte: Adaptado de Crepani et al. (2001), Nascimento e Domingues (2009) e Oliveira (2011).

A classificação do solo foi determinada pelo grau de maturidade do mesmo, no qual solos mais espessos, ou seja, bem desenvolvidos, apresentam maior estabilidade, enquanto solos jovens, portanto de menor espessura, apresentam a maior vulnerabilidade, com predomínio de erosão. Quanto ao tema vegetação, o parâmetro utilizado foi a densidade de cobertura vegetal, uma vez que este é um fator de proteção da unidade contra os processos morfogenéticos, portanto altas densidades de cobertura são atribuídas valores de baixa vulnerabilidade, enquanto baixas densidades apresentam altos valores de vulnerabilidade.

Para o tema geomorfologia, os pesos atribuídos estão de acordo com o proposto por Oliveira (2011). Os critérios utilizados para o tema são semelhantes aos usados anteriormente, o qual considera os processos de pedogênese, e morfogênese. Dessa forma, modelados de dissecação apresentam valores de vulnerabilidade moderados a altos, que dependem da intensidade do grau da densidade de drenagem e do aprofundamento das incisões. Modelados de acumulação como as planícies e os terraços, de origem fluvial e marinha, atribuiu-se os valores baixos de vulnerabilidade, no entanto, altos valores de vulnerabilidade são atribuídos a planícies sujeitas à inundação e de intensa 
morfodinâmica costeira, nas quais os processos dinâmicos de morfogênese predominam sobre a pedogênese e, portanto, apesar do relevo plano, são instáveis.

Para o tema uso e ocupação da terra os pesos foram de acordo com o proposto por Nascimento e Domingues (2009). Para o estabelecimento dos valores atribuídos, levou-se em consideração o grau da remoção e modificação da cobertura vegetal, já que uma cobertura vegetal densa contribui para a desaceleração dos processos da morfogênese, dessa forma, a vegetação nativa inalterada recebeu valores de vulnerabilidade 1, enquanto áreas urbanas receberam valor igual a 5.

Após a atribuição de valores na escala de vulnerabilidade de cada mapa temático, atribuíram-se pesos relativos entre os cinco temas analisados em função da sua maior ou menor relevância relativa de cada tema. A determinação desses pesos foi realizada a partir do método da análise hierárquica, o AHP (Analytic Hierarchy Process), de Saaty e Vargas (1991), na qual as variáveis são comparadas a partir de valores atribuídos por tomada de decisão, em uma escala numérica de ponderação que varia de extremamente mais ou menos importante umas com relação a outras (Saaty, 2008).

A carta de vulnerabilidade ambiental, gerada a partir dos produtos elaborados e álgebra de mapas, apresentou quatro classes: muito alta, alta, moderada e baixa. Na qual a classe "vulnerabilidade muito alta" representa uma unidade onde prevalecem os processos modificadores de relevo (morfogênese), ou seja, prevalecem os processos de erosão. Enquanto na classe "vulnerabilidade baixa" é considerada estável, ou seja, os processos que ocorrem na unidade favorecem a pedogênese em detrimento da erosão (Tabela 2).

Tabela 2. Classes e Graus na determinação da vulnerabilidade utilizados no trabalho.

\begin{tabular}{|l|c|}
\hline \multicolumn{1}{|c|}{ Classe de vulnerabilidade } & Graus de vulnerabilidade \\
\hline Baixa & $1,4-2,0$ \\
\hline Moderada & $2,1-3,0$ \\
\hline Alta & $3,1-4,0$ \\
\hline Muito alta & $4,1-5,0$ \\
\hline
\end{tabular}

\section{Resultados e discussão}

\section{Cartas de uso e ocupação da terra e de vegetação}

Quanto ao uso e ocupação da terra (Figura 2), a classe "área antrópica agrícola" é a mais expressiva, ocupando $45,8 \%$ da área. Esta classe considera áreas destinadas a plantio agrícola, temporário ou permanente, assim como, as áreas destinadas à pecuária. A classe "vegetação secundária" corresponde a áreas que surgem com o abandono da terra, após o uso pela agricultura, pecuária ou pelo reflorestamento (IBGE, 2012), a qual ocupa cerca de $3,5 \%$ do terreno. Juntas, estas duas classes representam a vegetação com influência antrópica presente na área.

As classes "cidades", "vilas" e "povoados", constituem as áreas urbanizadas dos municípios, as quais geralmente se localizam próximas às margens dos rios, e constituem juntas, $2,3 \%$ da área. As águas continentais presentes são os rios $(3,6 \%)$, de caráter meandrante, lagos e açudes $(0,1 \%)$ por vezes ligadas à piscicultura. As demais classes são: "solo exposto", ocupando uma área de 1,0\%, são relacionados a áreas de extração de areia, geralmente localizados na porção oeste da área de estudo, e pontualmente, associada a um aterro sanitário no Município de Vigia, e a classe "área úmida" (0,3\%) que se encontra em elevações de apenas $3 \mathrm{~m}$ acima do nível do mar, com presença água estagnada e vegetação herbácea. 


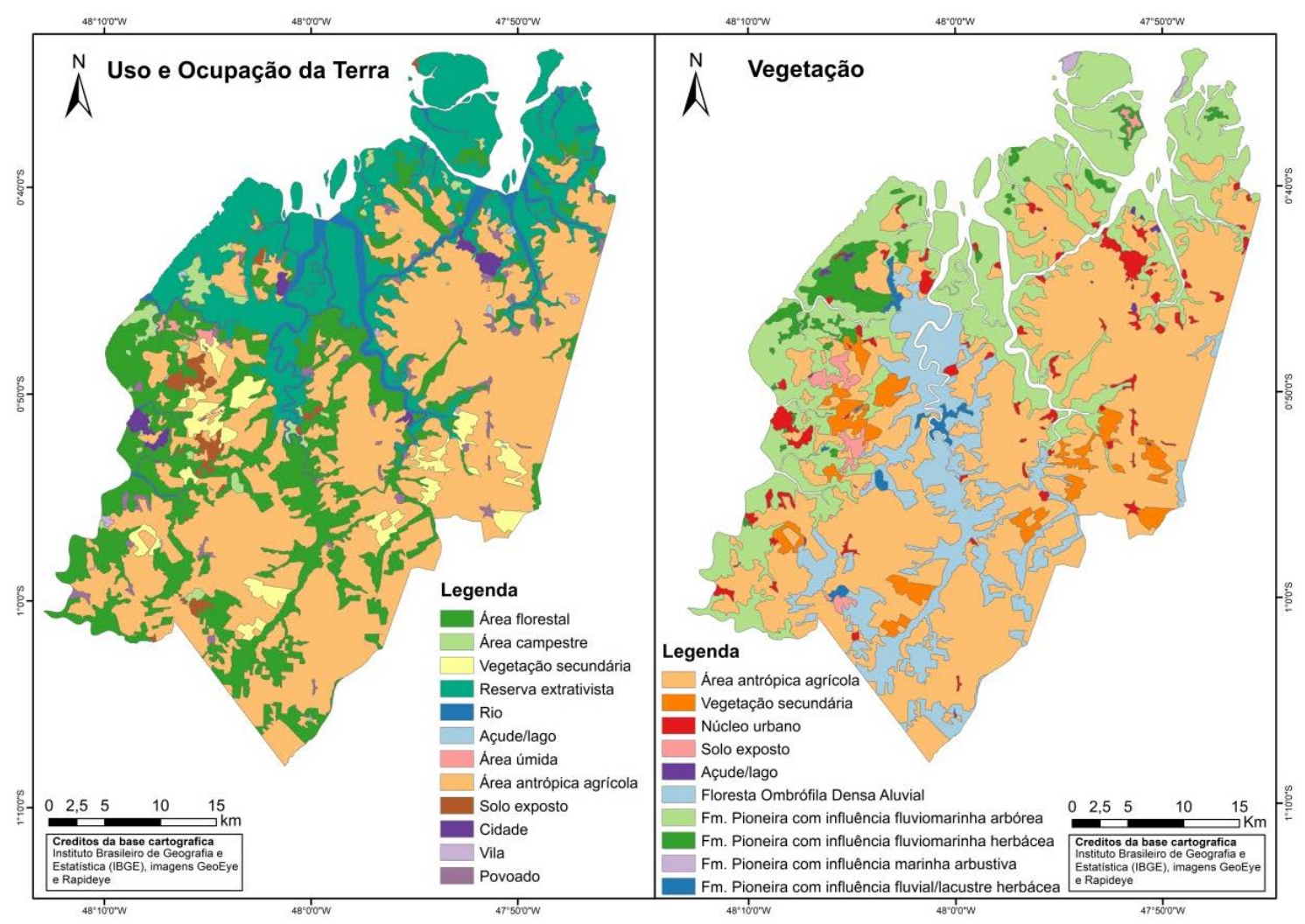

Figura 2. Carta de uso e ocupação da terra e de vegetação dos municípios da zona costeira oeste da Região Salgado Paraense.

As classes que representam vegetação natural são formadas por "área florestal" que agrega as vegetações do tipo arbóreas e ocupa $21,6 \%$ do terreno, e "área campestre" que corresponde às vegetações do tipo herbáceas e arbustivas e ocupa 1,4\% da área. Além da classe "reservas extrativistas" (20,4\%), que corresponde à parte continental das RESEX Mãe Grande de Curuçá e São João da Ponta, e a RESEX Marinha Mocapajuba, nelas estão inclusas áreas de vegetação nativa, assim como dunas, e praias.

Quanto à vegetação nativa a paisagem da zona costeira oeste da Região Salgado Paraense pode ser descrita como uma combinação de formações pioneiras e floresta ombrófila (Figura 2). A Floresta Ombrófila Densa Aluvial corresponde à formação ribeirinha, ocupa terrenos sedimentares das planícies recentes, ao longo dos cursos d'água (constituindo as matas de várzeas e igapó). Segundo o IBGE $(2012,2019)$, caracterizam-se pelo adensamento de árvores altas, e espécies de rápido crescimento são predominantes.

De acordo com IBGE (2012), ao longo do litoral e planícies fluviais, são frequentes as áreas cobertas por uma vegetação caracterizada por uma intensa sucessão, que ocorre em terrenos instáveis devido às seguidas deposições de areias marinhas nas praias e restingas, aluviões fluviomarinhos nas embocaduras dos rios e os solos ribeirinhos aluviais e lacustres. Essas vegetações se consideram pertencentes às "Formações Pioneiras".

A vegetação que constitui os manguezais ocorre na foz dos cursos de água, e locais de baixa energia, influenciados pelo fluxo das marés (Schmidlin et al., 2005). 0 substrato em que essa vegetação ocorre é salobro, portanto, desenvolvem-se uma vegetação especializada, adaptada à salinidade da água e solo. Na área de estudo são representadas pela Formação Pioneira, com influência fluviomarinha arbórea que é formada por espécies como Rhizophora mangle, Avicennia sp. e Laguncularia racemosa (IBGE, 2012). E pela 
formação pioneira com influência fluviomarinha herbácea a qual é constituída por gramíneas do gênero Spartina e Salicornia portulacoides (Schmidlin et al., 2005).

A Formação Pioneira com influência marinha arbustiva, também conhecida com restinga, recebem influência direta das águas do mar, ocorrem nas dunas e contribuem para sua fixação. A Formação Pioneira com influência fluvial e/ou lacustre herbácea, são comunidades vegetais das planícies aluviais que refletem os efeitos das cheias dos rios nas épocas chuvosas, ou das depressões alagáveis, são dominadas por comunidades campestres nos terrenos mais secos ou comunidades de herbáceas hidrófitas, nos terrenos pantanosos (IBGE, 2012, 2019).

Os resultados obtidos são compatíveis com Souza Filho e El-Robrini (1998), Lara (2003) e França e Souza Filho (2006), para a zona costeira paraense, que salientam o efeito da erosão como intensificador dos processos de alteração da paisagem, sendo que a associação com as formas de uso da terra e tipos de vegetação que favoreçam a perda de solo, principalmente pelas práticas de manejo inadequadas (Bertol e Almeida, 2000; Corrêa et al., 2015), podem acarretar em uma ampliação do efeito destes processos erosivos, cuja consequência direta pode impactar as áreas sensíveis de manguezais presentes, que são a base de sustento das comunidades que vivem das atividades da RESEX.

\section{Cartas de geomorfologia}

A área de estudo apresenta uma amplitude altimétrica de $65 \mathrm{~m}$ e uma declividade que varia de $0^{\circ}$ a $32^{\circ}$, assim, na zona costeira estudada predominam relevo com superfície plana $\left(0^{\circ}-3^{\circ}\right)$, suavemente ondulada $\left(3^{\circ}-8^{\circ}\right)$, e ondulada $\left(8^{\circ}-20^{\circ}\right)$, e de forma restrita, superfícies de declive que chegam a $32^{\circ}$. A área de estudo foi individualizada em sete conjuntos de feições (Figura 3) com base nos parâmetros de natureza estrutural, litológica e do padrão dos elementos que compõem o relevo.
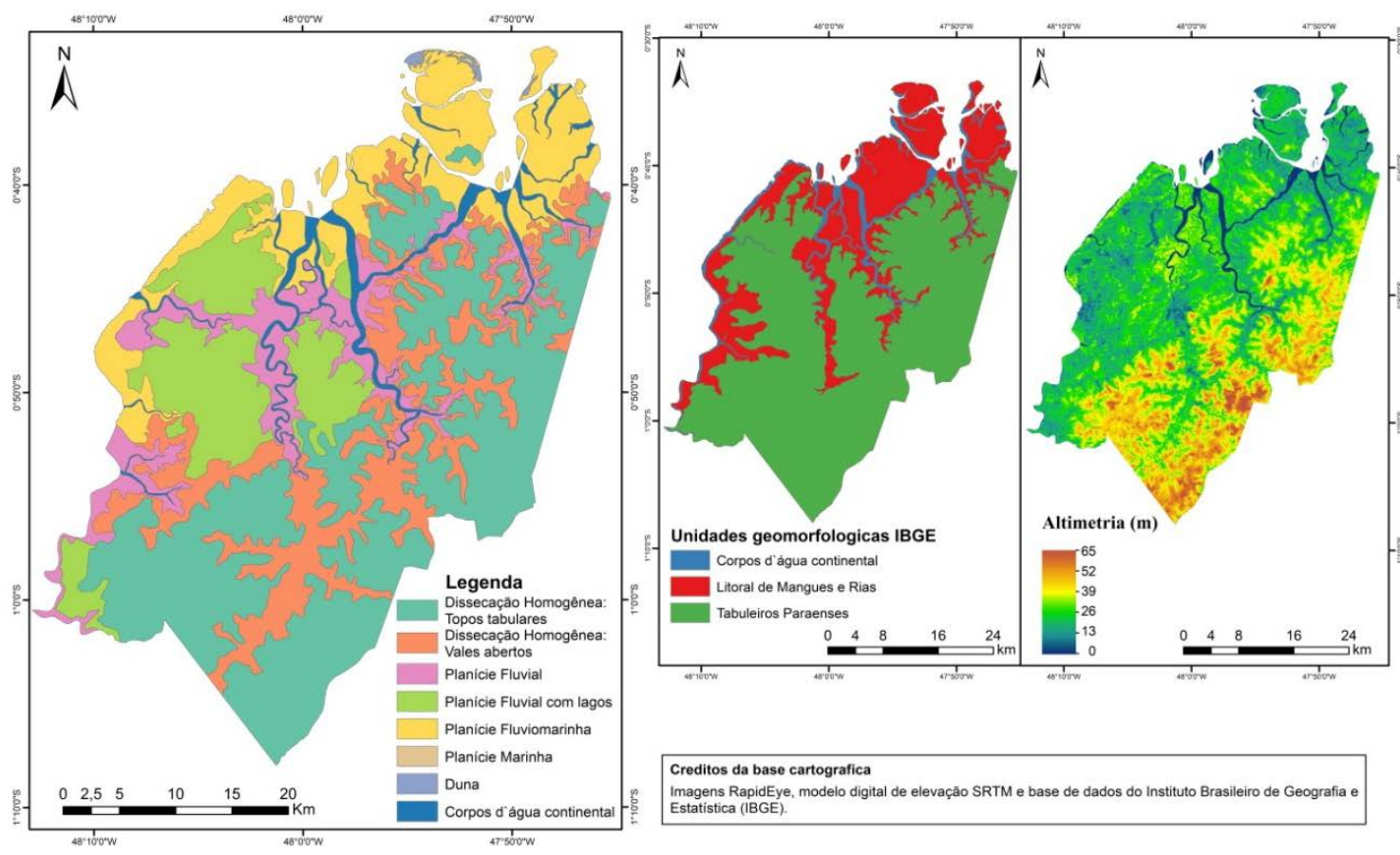

Figura 3. Carta de geomorfologia da Zona Costeira Oeste da Região Salgado Paraense, Unidades Geomorfológicas do Estado do Pará segundo o IBGE e mapa hipsométrico da área. 
As unidades da zona costeira oeste da Região Salgado Paraense são representadas essencialmente por duas Unidades Geomorfológicas estabelecidos por IBGE (2019), a Unidade Geomorfológica Tabuleiros Paraenses e a Unidade Geomorfológica Litoral de Mangues e Rias.

Os resultados obtidos são compatíveis com El Robrini e Mácola (2004), França e Souza Filho (2006), Boulhosa e Souza Filho (2008) e Rodrigues e Souza Filho (2011), para a zona costeira paraense, os quais têm uma abordagem relacionada à compartimentação fisiográfica e morfológica das zonas costeiras descrita em IBGE (2009):

\begin{abstract}
(a) A Unidade Geomorfológica Tabuleiros Paraenses compreende a aproximadamente $56 \%$ da área, e é assinalada por um relevo homogêneo, caracteriza-se por largas superfícies planas a suavemente dissecadas, com morfologia do tipo tabular com vales rasos e largos. É associada à unidade de terreno "Dissecação Homogênea: topos tabulares" - formada por morros de topos arredondados e vertentes côncavas, a dissecação é caracterizada por baixa densidade de drenagem e pouco aprofundamento das incisões - e à unidade de terreno "Dissecação Homogênea: vales abertos", o qual é caracterizado por um conjunto de vales abertos, formados por vertentes retilíneas e côncavas de baixa declividade, com maior aprofundamento das incisões próximo a nascente e com incisões mais suaves ao afastar-se desta. Acha-se dominantemente esculpida sobre os sedimentos terciários areno-argilosos da Formação Barreiras, e apresentam-se frequentemente inumadas por coberturas de alteração lateríticas.
\end{abstract}

(b) A Unidade Geomorfológica Litoral de Mangues e Rias (44\%) é caracterizada por reentrâncias do tipo rias, formação de manguezais, praias, restingas, dunas e alguns trechos de falésias, a qual, também, envolve uma série de ilhas, baías e canais. Compreende a faixa de sedimentos holocênicos que acompanha a linha de costa, e é constituído por material arenoso de origem marinha nas praias e restingas, e por sedimentos típicos dos manguezais principalmente nas embocaduras dos rios. É relativa aos modelados "Planície Fluviomarinha", "Planície Fluvial", "Planície Fluvial com lagos", "Planície Marinha" e "Dunas". A Planície Fluviomarinha corresponde a um relevo baixo e plano de declividade considerada nula, resultante do processo de deposição fluvial e marinha, ocorre geralmente próximo às desembocaduras dos rios, são constituídas por sedimentos lamosos ricos em matéria orgânica colonizados originalmente por vegetação de mangue. A Planície Fluvial é constituída por uma região plana correspondente à acumulação fluvial que ocorre no fundo dos vales, onde processos erosivos se combinam, simultaneamente, aos processos construtivos na definição dessas unidades. A Planície Fluvial com lagos corresponde a um relevo moderadamente ondulado, em regiões de planície, com presença de morros testemunho com topos arredondados, além da presença de regiões com tendência a alagamentos, principalmente na região norte, apresentando uma amplitude altimétrica de aproximadamente $28 \mathrm{~m}$. A Planície Marinha corresponde às praias da região são constituídas por relevo plano, ocorre nas margens dos manguezais em porções onde os processos costeiros são mais intensos. As dunas são caracterizadas por um relevo ondulado, de formas longitudinais paralelas à linha de costa, são compostas por sedimentos arenosos e são parcialmente cobertas por vegetação e segundo ElRobrini et al. (2006) são transversais à direção principal do vento.

\title{
Cartas de geologia e pedologia
}

O quadro geológico dos depósitos ocorrentes na área é representado por depósitos oligo-miocênicos (Grupo Barreiras) e quaternários (Pós-Barreiras e depósitos holocênicos) que recobrem a maior parte do NE do Estado do Pará (Figura 4).

Estão presentes fácies siliciclásticas (Formação Barreiras) do Grupo Barreiras, formadas por argilitos, arenitos quartzosos, depósitos heterolíticos e, menos comumente, conglomerados (Rossetti, 2006). Os Sedimentos Pós-Barreiras recobrem 
discordantemente a sucessão do Grupo Barreiras e horizontes de perfis das Coberturas Lateríticas Imaturas, estes são depósitos arenosos consolidados e semi-consolidados, compostos por areias com granulometria fina a média (Vasquez e Rosa-Costa, 2008).

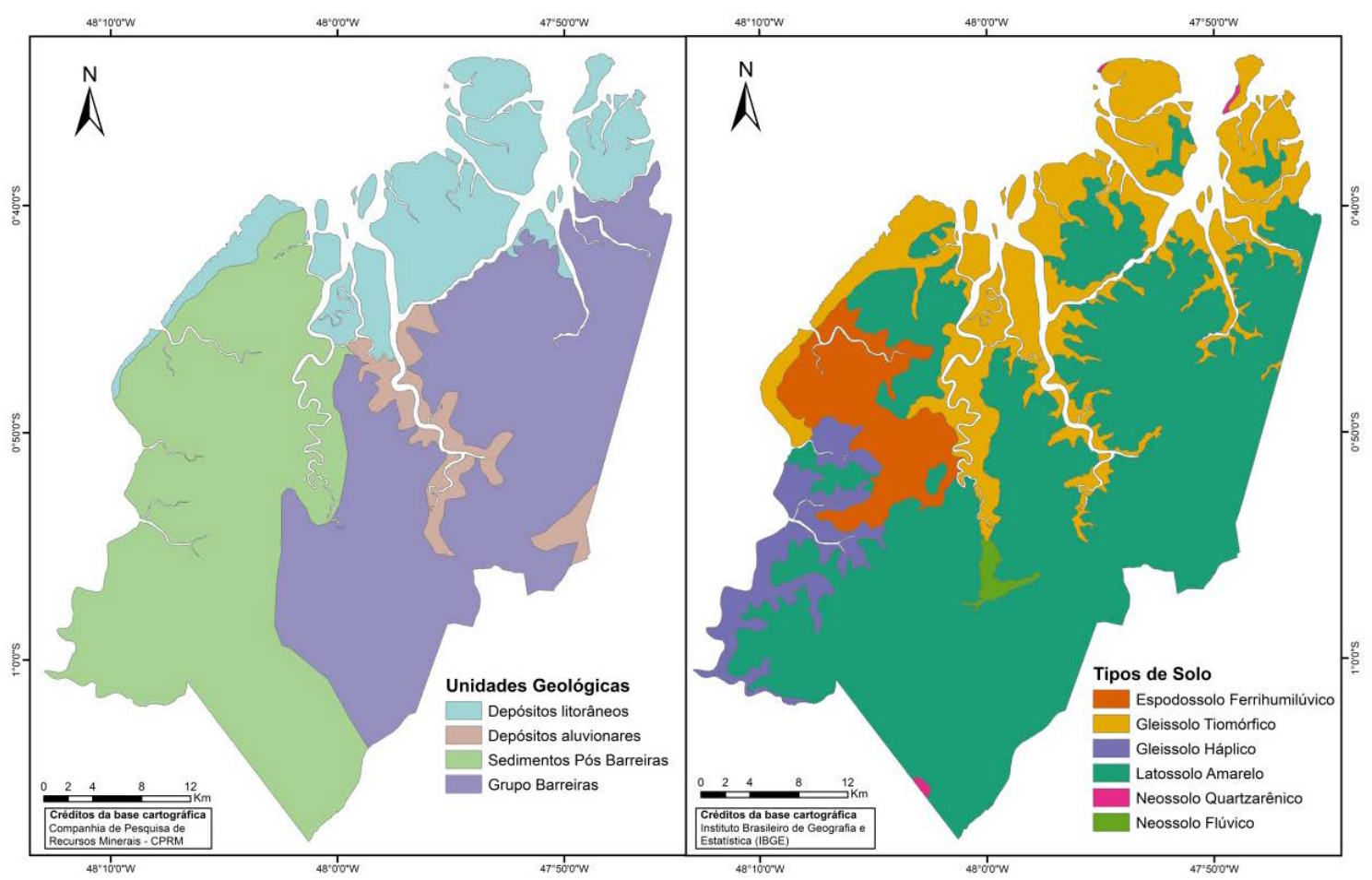

Figura 4. Mapa litoestratigráfico e mapa pedológico da Zona Costeira oeste da Região Salgado Paraense.

Os depósitos recentes são marcados por Depósitos Aluvionares, relacionados às planícies aluvionares atuais dos principais cursos d'água, constituídos por sedimentos arenosos a argilosos, com níveis de cascalho e matéria orgânica, inconsolidados a semiconsolidados; e por Depósitos Litorâneos, depósitos sedimentares de praias, dunas, manguezais e pântanos salinos, que constituem a planície costeira do Estado, estes depósitos são essencialmente arenosos quando associados a depósitos de praias e dunas, e predominantemente pelíticos, com grande contribuição de matéria orgânica, quando constituem os depósitos de manguezais e pântanos salinos (Vasquez e Rosa-Costa, 2008).

Quanto à pedologia (Figura 4), destaca-se, nessa região, o predomínio dos latossolos amarelos seguidas de gleissolo tiomórfico, espodossolo ferrihumilúvico, gleissolo háplico e em menor escala neossolo quartzarênico e neossolo flúvico (EMBRAPA, 2018):

(a) Os latossolos amarelos em geral são solos em avançado estagio de intemperização, muito evoluídos, profundos e de boa drenagem. São solos típicos regiões equatoriais e tropicais, distribuídos, normalmente em relevo plano e suave ondulado, embora possam ocorrer em áreas mais acidentadas.

(b) Os espodossolo ferrihumilúvico são solos de textura predominantemente arenosa, em geral são pobres em fertilidade. Ocorrem em relevo plano, suave ondulado, áreas de surgente, abaciamentos e depressões em regiões costeiras. 
(c) Os gleissolos apresentam um sistema de drenagem restrito, são característicos de áreas alagadas ou sujeitas a alagamento. Comumente, desenvolvem-se em sedimentos recentes nas proximidades dos cursos d'água.

(d) Os nesossolos são mais recentes e, comumente, possuem profundidades pouco expressivas quando comparados aos latossolos e espodossolos. São solos constituídos por material mineral ou por material orgânico que não apresenta alterações expressivas em relação ao material originário. 0 neossolo flúvico são derivados de sedimentos aluviais argilosos, e os neossolos quartzarênicos são essencialmente quartzosos.

\section{Carta de vulnerabilidade ambiental}

Os temas geologia, geomorfologia, pedologia, uso e ocupação da terra e vegetação foram utilizados para realizar a análise da vulnerabilidade ambiental da zona costeira oeste da Região Salgado Paraense, e foram reclassificados em cinco classes, numa escala de 1 a 5 , onde o maior valor corresponde a uma maior influência nos processos que levam a vulnerabilidade ambiental. (Figura 5).

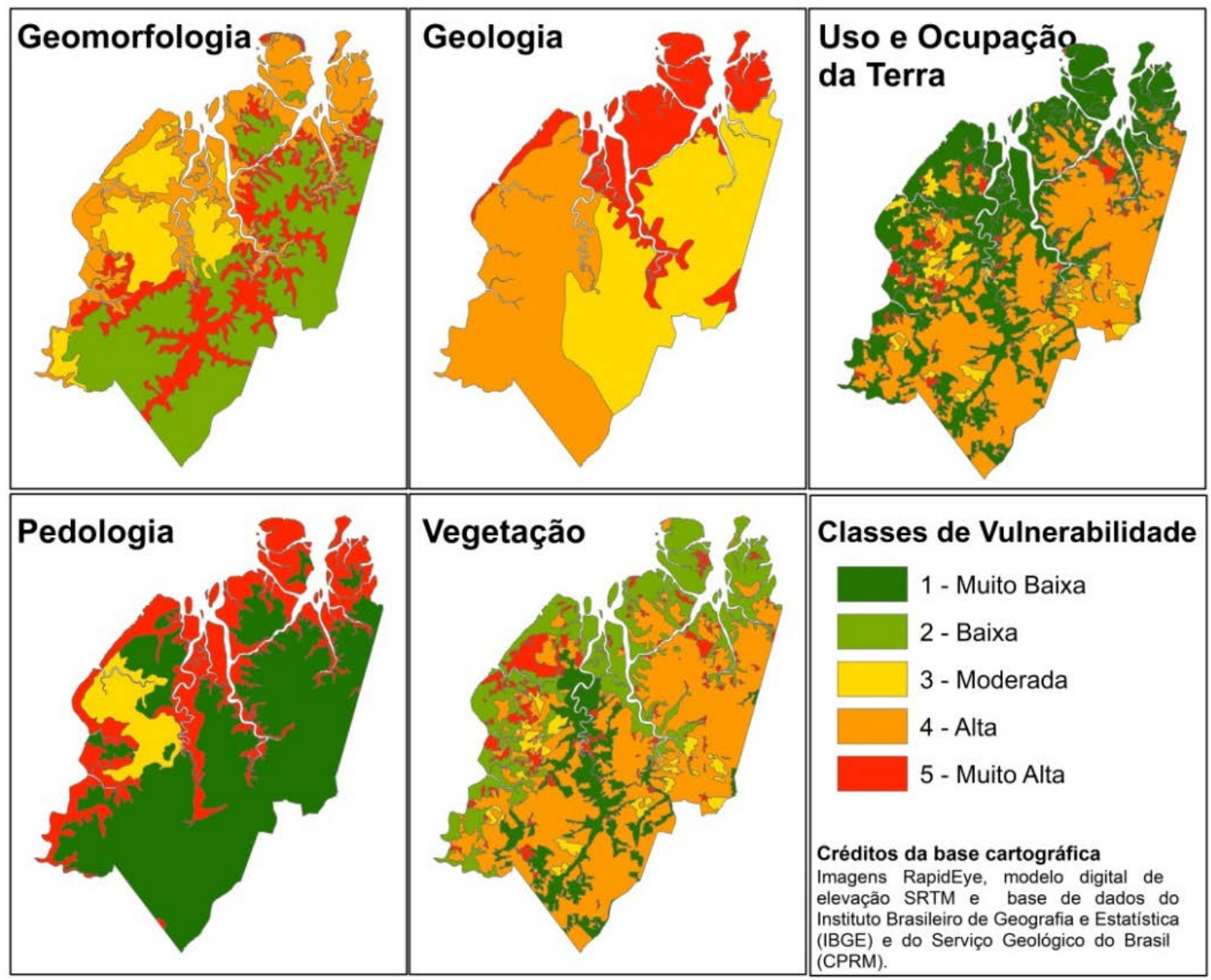

Figura 5. Temas utilizados para compor a carta derivada reclassificados em função dos diferentes classes de vulnerabilidade ambiental.

Ao aplicar a metodologia AHP foram determinados pesos relativos para os temas selecionados resultando em uma matriz de comparação pareada, na qual foi realizado um 
cálculo de normalização que gerou o peso de cada tema, os quais utilizados para gerar uma equação que guiou a álgebra de mapas de acordo com a influência de cada tema diante da vulnerabilidade ambiental da Zona Costeira oeste da Região Salgado Paraense (Equação 1). Onde as variáveis de Vulnerabilidade ambiental (VA) são Geologia (G), Geomorfologia (Gm), Uso e ocupação da terra (UOT), Vegetação (V) e Pedologia (P):

$$
\mathbf{V A}=(0,05 \mathrm{G})+(0,34 \mathrm{Gm})+(0,36 \mathrm{UOT})+(0,13 \mathrm{~V})+(0,12 \mathrm{P}) \text { eq. } 01
$$

Na carta de vulnerabilidade ambiental da zona costeira oeste da Região Salgado Paraense (Figura 6) podem ser avaliadas as áreas com maior ou menor tendência às mudanças na paisagem, que são avaliadas a partir dos componentes naturais do meio físico e dos processos antrópicos (Grigio, 2003). Neste trabalho a característica utilizada para determinar a vulnerabilidade da paisagem a essas mudanças foi a tendência que cada feição da paisagem apresenta à erosão.
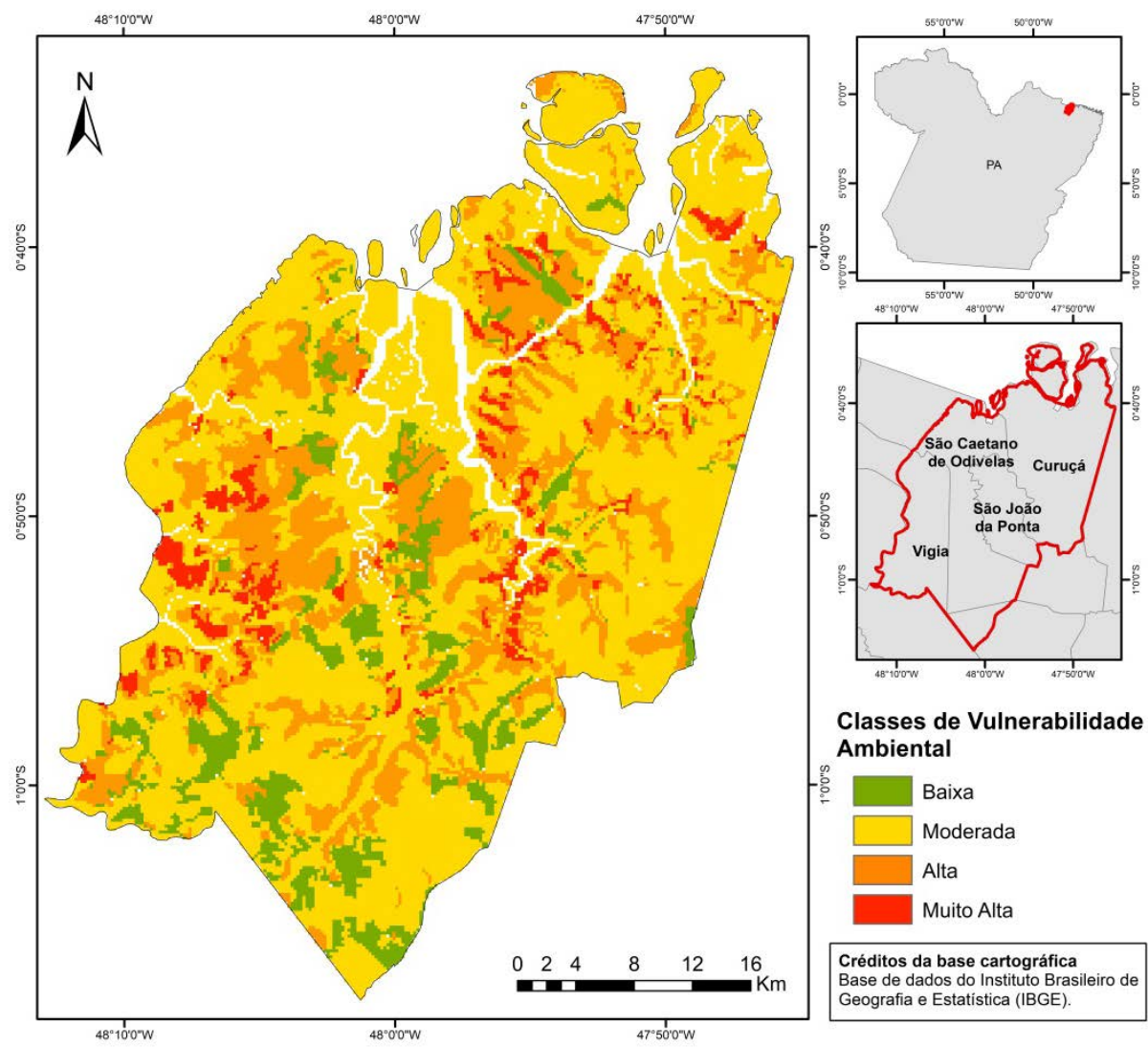

Figura 6. Carta de vulnerabilidade ambiental da zona costeira oeste da Região Salgado Paraense.

A zona costeira oeste da Região Salgado Paraense apresenta a maior parte de sua área, cerca de 62,94\%, com uma vulnerabilidade ambiental moderada, seguida de 23,70\% e $8,45 \%$ de sua área pertencendo às classes alta e baixa, respectivamente, enquanto que apenas $4,91 \%$ representa áreas de vulnerabilidade muito alta.

A classe "Vulnerabilidade baixa" está associada à menor atuação antrópica da região, sendo recobertas em sua maioria por áreas com vegetação arbórea, que age como 
um protetor do solo, e características naturais, como substrato e morfologia, estáveis e menos suscetíveis a mudanças. No entanto, deve-se destacar que mesmo sendo a áreas menos propensa a erosão, ela não está ilesa de tais processos, principalmente frente a modificações antrópicas futuras, o que interfere de forma direta no equilíbrio entre os processos de morfogênese e pedogênese.

A classe "Vulnerabilidade moderada" é a mais abrangente, incluindo parte da área de influência das sedes municipais (localmente elas transitam entre alta e muito alta). Está vinculada a uma grande diversidade de características do meio físico e antrópicas que variam quanto ao seu grau de estabilidade às mudanças nas paisagens. Assim, quanto essa classe é relacionada áreas de agropecuária, essa atividade, que promove uma maior vulnerabilidade, está associada a solos e litologias estáveis, como é o caso dos latossolos amarelos e ao Grupo Barreias. Quando relacionada a terrenos instáveis, como as planícies fluviomarinhas, estas ocorrem em conjunto com vegetações nativas arbóreas, em áreas de reservas extrativistas ou não. Gerando assim, um equilíbrio quanto à intensidade de cada aspecto do meio à vulnerabilidade.

A classe "Vulnerabilidade alta" associa-se as formas de uso e ocupação da terra que promovem a exposição solo, tanto de origem naturais, como é o caso das praias, dunas e áreas cobertas por vegetação herbáceas; assim como de origem antrópica, como é o caso das áreas de agricultura e pecuária. E apesar dessa classe abranger, frequentemente, tipos de solos e litologias mais estáveis, ocorrem associadas a formas de uso e ocupação da terra e classes de dissecação de maior instabilidade, os quais são os temas com a maior influência na determinação da vulnerabilidade ambiental. Assim, essa área apresenta uma grande instabilidade frente às mudanças na paisagem da zona costeira estudada. Dessa forma, requerem mais atenção quanto à ocorrência dos processos erosivos.

As áreas classificadas com "Vulnerabilidade muito alta" correspondem à parcela de $4,91 \%$ dessa zona costeira. No entanto, apesar de ser uma área relativamente pequena é a que carece de uma maior atenção a fim de evitar potenciais danos, que podem acarretar em grandes impactos socioeconômicos à região, já que apresentam características naturais mais favoráveis à erosão natural, potencializadas pela influência antrópica, assim como as áreas de vulnerabilidade alta.

Nesta classe ocorrem as ações antrópicas mais efetivas, e que acarretam numa maior exposição do terreno pela retirada de vegetação, as estas classes estão associados os núcleos urbanos, os solos expostos, e a áreas destinadas à agropecuária, assim como está relacionada a vegetações pouco densas, como é o caso das formações pioneiras herbáceas. A classe como um todo é relacionada a tipos de solo e de litologias mais vulneráveis, no entanto é possível notar uma divisão espacial quanto aos aspectos que influenciam na vulnerabilidade elevada: na porção oriental da área a classe está ligada à agricultura e a vertentes com maior declividade, enquanto que na porção ocidental esta está relacionada a atividades de extração de areia (solos expostos).

É importante destacar que os aspectos naturais podem ser alterados pela intervenção antrópica, assim o tipo de avaliação proposto pode ser ampliado ou mais detalhado, conforme o aumento das variáveis associadas. Aplicações diferenciais do método podem ser encontradas em Busman et al. (2016), que avaliaram a vulnerabilidade natural (VN), vulnerabilidade ambiental (VA) e a vulnerabilidade ambiental ao aumento relativo do nível médio do mar (VNMM) em zonas costeiras tropicais, Lopes e Saldanha (2016), voltado para o planejamento ambiental em bacias hidrográficas, Valle et al. (2016), que discutem em termos da "fragilidade ambiental como uma medida da sensibilidade intrínseca dos ecossistemas às pressões ambientais", Lima e Silva (2018), na abordagem das geotecnologias como facilitadoras do processo de análise multivariada, Nunes e Aquino (2018), que apresentam uma abordagem direcionada para análise da vulnerabilidade aplicada a ambientes urbanos, bem como em Silva (2019), em um foco mais específico, na análise de movimentos de massa. 


\section{Paraense}

Diretrizes geoambientais para proteção da zona costeira da Região Salgado

A proteção dos ambientes costeiros é objeto de vários documentos legais internacionais, nacionais, estaduais e municipais de proteção, haja vista sua enorme importância como área de ocupação social, como habitat de fauna e de flora, como fonte de alimentação e como área turística.

A avaliação da vulnerabilidade ambiental de uma região pode ser uma ferramenta valiosa na área de gerenciamento ambiental, uma vez que contribui para a melhor definição do objeto da proteção e no desenvolvimento de cenários de impacto potencial com base em várias características ambientais. Com este gerenciamento dois objetivos diferentes podem ser alcançados: (1) restauração de ecossistemas impactados; e (2) proteção de recursos naturais e sociais contra possíveis impactos (Boori e Amaro, 2011b).

Diante disso, sugere-se que os territórios classificados com vulnerabilidade muito alta e alta devem ser protegidos como primeira prioridade. Na porção oriental da área uma possível medida a ser tomada com relação a essas classes é a conversão de terras agrícolas e de pastagem em áreas de florestas, ou o emprego de técnicas utilizadas em terrenos de encostas, como o terraceamento agrícola e o plantio em níveis, uma vez que essas áreas estão associadas a declives mais acentuados, portanto mais suscetíveis a processos erosivos. Na porção ocidental, as áreas de vulnerabilidade muito alta e alta são associadas a áreas de solo exposto, utilizadas para a extração de matérias de construção e pontualmente para aterro sanitário, assim, o uso dessas áreas deve ser normatizado com maior rigor. Na área urbana devem ser tomadas medidas para melhorar a drenagem pluvial, diminuído a impermeabilização do solo. Assim como, devem ser realizados projetos de planejamento urbano que evitem novas ocupações em locais inadequados.

0 uso das áreas de vulnerabilidade moderada deve ser limitado a atividades que não desprotejam o solo, nem o impermeabilize. Grande parte dessa classe está associada a atividades agropecuárias, portanto, algumas técnicas de manejo do solo devem ser adotadas pelos agricultores, tais como a rotação e associação de culturas e a cobertura verde, para que o solo permaneça com suas propriedades físicas e químicas.

Ademais, as unidades de conservação são muito eficazes na proteção da zona costeira, pois atuam não só na preservação de ecossistemas, como também no uso destes, visando à proteção dos recursos existentes. Tal fato pode ser observado na área de estudo, já que os territórios pertencentes à RESEX apresentam classes de vulnerabilidade moderadas e baixas, apesar de apresentarem características físicas naturais vulneráveis.

Além disso, trabalhos e pesquisas de vulnerabilidade ambiental fornecem subsídios para o Zoneamento Ecológico-Econômico Costeiro (ZEEC), que tem por objetivo compatibilizar o crescimento econômico com a conservação dos recursos naturais em favor das presentes e futuras gerações. E que no Estado do Pará se encontra em fase preliminar de pré-planejamento (Nicolodi et al., 2018). Também produz subsídios para Plano Diretor do Município, que fornece diretrizes para construção dos espaços urbanos e rurais, norteando usos e formas de ocupação, visando assegurar melhores condições de vida à população e que deve conter normas relativas ao desenvolvimento que levem em conta a proteção ambiental (Milanez e Pereira, 2016).

\section{Conclusão}

Destaca-se que, de acordo com o método utilizado e com os resultados obtidos, a maior parte da área pode estar estável, com vulnerabilidades baixas e moderadas $(71,5 \%)$, com um tênue equilíbrio ambiental, o qual pode ser desordenado facilmente por uma intensificação das atividades antrópicas vigentes. Ainda assim, cerca de 28,5\% correspondem a áreas de vulnerabilidade muito alta e alta, ou seja, representam a área com maior susceptibilidade a um potencial impacto provocado por um uso antrópico 
qualquer. Ademais, vale destacar que as áreas de elevada vulnerabilidade estão associadas, principalmente, a porções da região onde se encontram ocupações e atividades antrópicas significativas, como a concentração de áreas urbanas e a extração de areia, portanto ressaltando a relação direta entre os usos da terra e a magnitude dos impactos ambientais potenciais.

Assim, as cartas de vulnerabilidade ambiental permitem uma avaliação das áreas com maior susceptibilidade a potenciais impactos ambientais a partir da escolha adequada dos critérios que influenciam a ocorrência dos mesmos, bem como indicando ainda as áreas mais susceptíveis que requerem, portanto, estudos mais detalhados, subsidiando a tomada de decisões por parte dos órgãos governamentais, bem como da sociedade civil, indicando áreas mais adequadas ao desenvolvimento de projetos específicos e ao o uso da terra em conformidade com as características físicas do terreno, evitando, dessa forma, perdas materiais, ambientais e econômicas, e reduzindo conflitos socioambientais envolvidos nas áreas de maior vulnerabilidade.

\section{Agradecimentos}

Ao Conselho Nacional de Desenvolvimento Científico e Tecnológico (CNPq) pelo apoio no desenvolvimento da pesquisa.

\section{Conflito de interesses}

As autoras declaram não haver conflito de interesses.

\section{Referências}

Bertol, I.; Almeida, J. A. Tolerância de perda de solo por erosão para os principais solos do Estado de Santa Catarina. Revista Brasileira de Ciência do Solo, v. 24, n. 3, p. 657-668, 2000. https://doi.org/10.1590/S0100-06832000000300018

Boori, M. S.; Amaro, V. E. A remote sensing approach for vulnerability and environmental change in Apodi Valley Region, Northeast Brazil. International Journal of Geological and Environmental Engineering, v. 5, n. 2, 93103, 2011a. https://doi.org/10.5281/ zenodo.1333552

Boori, M. S.; Amaro, V. E. Natural and eco-environmental vulnerability assessment through multi-temporal satellite data sets in Apodi Valley Region, Northeast Brazil. Journal of Geography and Regional Plannin, v. 4, n. 4, p. 216-230, 2011b.

Boulhosa, M. B. M. Análise de imagens Landsat etm+, Radarsat-1 e modelos numéricos de terreno para o mapeamento dos índices de sensibilidade ambiental ao derramamento de óleo na costa de manguezais do Nordeste do Pará. Belém: Universidade Federal do Pará, 2006. (Dissertação de mestrado)

Boulhosa, M. B. M.; Souza Filho, P. W. M. Reconhecimento e mapeamento dos ambientes costeiros para geração de mapas de ISA ao derramamento de óleo, Amazônia Oriental. $\begin{array}{lllll}\text { Revista Brasileira de Geofísica, } & \text { v. 27, } & \text { n. 1, } & \text { p. 23-27, }\end{array}$ https://doi.org/10.1590/S0102-261X2009000500003

Busman, D. V.; Amaro, V. E.; Souza-Filho, P. W. M. Análise estatística multivariada de métodos de vulnerabilidade física em zonas costeiras tropicais. Revista Brasileira de Geomorfologia, v. 17, n. 3, p. 499-516, 2016. https://doi.org/10.20502/rbg.v17i3.912 
Corrêa, E. A.; Pinto, S. A. F.; Couto Junior, A. Espacialização temporal das perdas de solos em uma microbacia hidrográfica com predomínio de solos arenosos. Geografia, v. 40, n. 1, p. 101-118, 2015.

Crepani, E.; Medeiros, J. S.; Hernandez Filho, P.; Florenzano, T. G.; Duarte, V.; Barbosa, C. F. Sensoriamento remoto e geoprocessamento aplicados ao zoneamento ecológico econômico e ao ordenamento territorial. São José dos Campos: Instituto Nacional de Pesquisas Espaciais, 2001.

El Robrini, M.; Mácola, G. Ilha dos Guarás (Mariteua) - Município de Curuçá (NE do Pará): aspectos físicos, meteorológicos. \& oceanográficos. Belém: Companhia Docas do Pará; CHD \& Grupo de Estudos Marinhos e Costeiros, 2004.

El-Robrini, M.; Silva, M. A. M. A.; Souza Filho, P. W.; El-Robrini, M. H. S.; Silva Júnior, O. G.; França, C. F. Pará. In: Muehe, D. (Org.). Erosão e progradação do litoral brasileiro. Brasília: Ministério do Meio Ambiente, 2006. p. 41-86.

EMBRAPA - Empresa Brasileira de Pesquisa Agropecuária. Sistema brasileiro de classificação de solos. 5. ed. Rio de Janeiro: Centro Nacional de Pesquisa de Solos, 2018.

França, C. F.; Souza Filho, P. W. M. Compartimentação morfológica da margem leste da Ilha de Marajó: zona costeira dos Municípios de Soure e Salvaterra - Estado do Pará. Revista Brasileira de Geomorfologia, v. 7, n. 1, p. 33-42, 2006. https://doi.org/10.20502/ rbg.v7i1.58

Grigio, A. M. Aplicação do sensoriamento remoto e sistemas de informação geográfica na determinação da vulnerabilidade natural e ambiental do Município de Guamaré (RN): simulação de risco ás atividades da indústria petrolífera. Natal: Universidade Federal do Rio Grande do Norte, 2003. (Dissertação de mestrado).

IBGE - Instituto Brasileiro de Geografia e Estatística. Manual técnico de geomorfologia. 2. ed. Rio de Janeiro: IBGE, 2009.

IBGE - Instituto Brasileiro de Geografia e Estatística. Manual técnico da vegetação brasileira. 2. ed. Rio de Janeiro: IBGE, 2012.

IBGE - Instituto Brasileiro de Geografia e Estatística. Manual técnico de uso da terra. 3. ed. Rio de Janeiro: IBGE, 2013.

IBGE - Instituto Brasileiro de Geografia e Estatística. Banco de Informações Ambientais (BDIA). 2019. Disponível em: <https://bdiaweb.ibge.gov.br/\#/home>. Acesso em: 12 set. 2019.

Lara, R. J. Amazonian mangroves - A multidisciplinary case study in Pará State, North Brazil: Introduction. Wetlands Ecology and Management, v. 11, p. 217-221, 2003. https://doi.org/10.1023/A:1025012914237

Lima, M. M. P.; Silva, L. Análise da vulnerabilidade natural da Bacia Hidrográfica do Rio Banabuiú, com apoio de geotecnologia. Revista Brasileira de Geografia Física, v. 11, n. 4, p. 1442-1457, 2018. https://doi.org/10.26848/rbgf.v11.4.p1442-1457

Lopes, M. S.; Saldanha, D. L. Análise de vulnerabilidade natural à erosão como subsídio ao planejamento ambiental do oeste da Bacia Hidrográfica do Camaquã-RS. Revista Brasileira de Cartografia, v. 68, n. 9, p. 1689-1708, 2016.

Milanez, C. H. S.; Pereira, J. G. Caracterização da vulnerabilidade ambiental na Microbacia do Córrego Azul, Ivinhema-MS. Geografia, v. 25, n. 1, p. 43-63, 2016. https://doi.org/ 10.5433/2447-1747.2016v25n1p43 
Nascimento, D. M. C.; Dominguez, J. M. L. Avaliação da vulnerabilidade ambiental como instrumento de gestão costeira nos Municípios de Belmonte e Canavieiras, Bahia. Revista Brasileira de Geociências, v. 39, n. 3, p. 395-408, 2009.

Nicolodi, J. L.; Asmus, M. L.; Turra, A.; Pollete, M. Avaliação dos Zoneamentos EcológicoEconômicos Costeiros (ZEEC) do Brasil: proposta metodológica. Desenvolvimento e Meio Ambiente, v. 44, p. 378-404, 2018. https://doi.org/10.5380/dma.v44i0.54865

Nunes H. K. B.; Aquino C. M. S. Vulnerabilidade ambiental dos setores censitários às margens do Rio Poti no Município de Teresina (Piauí). Revista Brasileira de Geografia Física, v. 11, n. 6, p. 1941-1962, 2018. https://doi.org/10.26848/rbgf.v11.6.p1941-1962

Oliveira D. S. Análise de índices de vulnerabilidade física com uso de geotecnologias na Região da Barreira do Inferno. Natal: Universidade Federal do Rio Grande do Norte, 2017. (Dissertação de mestrado).

Oliveira F. F. G. Aplicação das técnicas de geoprocessamento na análise dos impactos ambientais e na determinação da vulnerabilidade ambiental do Sul do Rio Grande do Norte. Rio Claro: Universidade Estadual Paulista, 2011. (Tese de doutorado).

Rodrigues S. W. P.; Souza Filho P. W. M. Reconhecimento e mapeamento dos ambientes sedimentares recentes ao longo da baía de Curuçá através de imagens Landsat TM, ETM+e CBERS 2B. Anais do XIII Congresso da Associação Brasileira de Estudos do Quaternário, Búzios, 2011. p. 1-5.

Rossetti D. F. Evolução sedimentar miocênica nos Estados do Pará e Maranhão. Geologia USP: Série Científica, v. 6, n. 2, p. 7-18, 2006. https://doi.org/10.5327/S1519874X2006000300003

Saaty, T. L.; Vargas L. G. Prediction, projection and forecasting. Boston: Kluwer Academic, 1991.

Saaty, T. L. Decision making with the analytic hierarchy process. International Journal Services Sciences, v. 1, n. 1, p. 83-98, 2008. https://doi.org/10.1504/IJSSCI.2008.017590

Schmidlin, L. A. J.; Accioly A.; Accioly P.; Kirchner F. F. Mapeamento e caracterização da vegetação da Ilha de Superagüi utilizando técnicas de geoprocessamento. Floresta, v. 35, n. 2, p. 303-315, 2005. https://doi.org/10.5380/rf.v35i2.4618

Silva F. G. Análise integrada da vulnerabilidade ambiental: risco de movimento de massa na Cidade de Montes Claros/MG. Revista Geografia em Debate, v. 13, n. 2, p 561-574, 2019.

Souza Filho, P. W. M.; El-Robrini M. As variações de nível relativo do mar e estratigrafia de sequências da Planície Costeira Bragantina, Nordeste do Pará. Boletim do Museu Paraense Emilio Goeldi, Série Ciências da Terra, v. 10, p. 45-78, 1998.

Tagliani C. R. A. Técnica para avaliação da vulnerabilidade ambiental de ambientes costeiros utilizando um sistema geográfico de informações. Anais do XI Simpósio Brasileiro de Sensoriamento Remoto, Belo Horizonte, 2003. p. 1657-1664.

Valle I. C.; Francelino M. R.; Pinheiro H. S. K. Mapeamento da fragilidade ambiental na Bacia do Rio Aldeia Velha, RJ. Floresta e Ambiente, v. 23, n. 2, p. 295-308, 2016. https://doi.org/10.1590/2179-8087.107714

Rev. Bras. Gest. Amb. Sustent., 2021, vol. 8, n. 20, p. 1315-1332. 
Vasquez, M. L.; Rosa-Costa, L. P. (Orgs.). Geologia e de recursos minerais do Estado do Pará: texto explicativo do mapa geológico e de recursos minerais do Estado do Pará. Escala 1:1.000.000. Belém: CPRM, 2008. p. 113-215.

Informação da Licença: Este é um artigo Open Access distribuído sob os termos da Licença Creative Commons Attribution, que permite uso irrestrito, distribuição e reprodução em qualquer meio, desde que a obra original seja devidamente citada. 